\title{
Seeking hard data on adverse effects of drugs
}

$\mathrm{F}$ or years, obtaining hard information about the incidence rates of adverse effects related to a specific drug was all but impossible as pharmaceutical manufacturers and governments seemed inclined to hide all manner of dirty linen, as if providing such information to patients was an altogether too dangerous thing.

But as consumers have begun to demand more information in the interests of taking a proactive role in decision-making over their health care options, governments have slowly - if somewhat reluctantly — cracked open their vaults on reports of adverse effects of specific drugs. Health Canada's MedEffect database, for example, was made publicly available in 2005 , albeit not in a form that many consumers or health researchers say is necessarily useful. The United States Food and Drug Administration (FDA) began releasing statistical reports on cases in its Adverse Event Reporting System (www.fda.gov /Drugs/GuidanceComplianceRegulatory Information/Surveillance/AdverseDrug Effects/default.htm). But its database is not searchable and is often incomprehensible to consumers.

As consumer demand for such information continues to increase, privately developed databases, such as one recently unveiled in the United States called Adverse Events, are step- ping in to fill the void (http://adverse events.com/).

Critics, though, are skeptical about the value of providing such information to consumers, the quality of that information and its ultimate utility.

As Wojtek Michalowski, professor of decision and management sciences at the University of Ottawa in Ontario argues in an email: "Such 'un-edited' reporting might result in a skewed data that will be of limited scientific use and will further muddle a picture if accessed by consumers. ... There is nothing worse than an uninformed person attempting to draw conclusion from (low quality) data."

But Brian Overstreet, founder and CEO of the website, argues that consumers are entitled to the best information they can get, even if it has its limitations, because it helps them and their doctors make informed choices about drugs.

"We live in an information age, and there is an overwhelming pool of potential information for consumers to look at online. What's lacking is a real statistical overview. We can come in and say, listen it's nice that 200 people on this discussion board say they got an upset stomach, but we have 50000 case reports, and from those we know 27\% have an upset stomach. Having hard data to back up the real world perception I think is very, very valuable."
Overstreet's website uses data culled from the FDA to create a database in which the name of a specific drug can be entered into a search engine to generate information about the percentage of respondents that reported a specific adverse effect, such as suicidal ideation, or the percentage that found it to be ineffective.

For a fee, consumers (\$100) and businesses $(\$ 250)$, can gain access to even more detail such as the relationships between adverse events and patient demographics or prescription regimens, as well as the relationship to outcomes such as hospitalization or death. "There's search functionality that allows you to slice and dice data however you want," says Overstreet.

The data are essentially limited to what information is reported to the FDA, whether as a result of compulsory reporting by industry, or voluntary reporting by physicians and consumers.

From a patient's perspective, it can be very valuable, says Jillian Clare Köhler, professor of pharmacy at the University of Toronto in Ontario. "I believe patients need professional input for prescription medicines. However, I believe any tool that allows for more transparent information about the potential risks/benefits of any medicine is an excellent outcome."

"Drugs can have an impact on

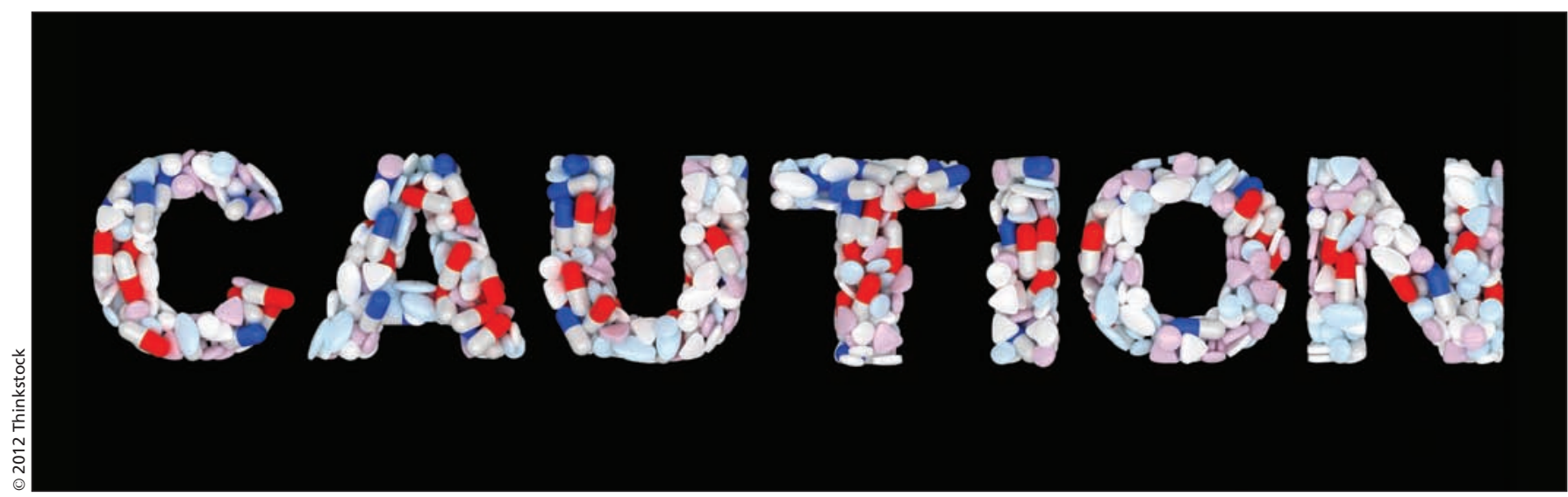

Some experts say the move toward greater disclosure of adverse effects is inevitable, as demand from patients keeps rising and they are entitled to such information. 
patients for better or worse. If patients have access to information, they can be more mindful," she adds. "Doctors don't always have the time to get full information about their patients. ... It's not about patients telling doctors (what to do). But it could potentially lead to a safer patient, if people are aware of potential implications."

But the FDA is wary about such use of its adverse effects data, says Sandy Walsh, a spokesperson for the agency. "First, there is no certainty that the reported event was actually due to the product. FDA does not require that a causal relationship between a product and event be proven, and reports do not always contain enough detail to properly evaluate an event. Further, FDA does not receive all adverse event reports that occur with a product. Many factors can influence whether or not an event will be reported, such as the time a product has been marketed and publicity about an event."

Overstreet says such limitations don't undermine the tool's value and, if anything, understate the incidence of adverse effects associated with a drug. "The FDA, and even they don't know for sure, but they estimate maybe $10 \%$ of the serious adverse events are reported. But as much as we're talking about a limited data set, three million case reports in the last seven years, it's not a small data set. It's a pretty robust data set."

"The data's never going to be perfect, but it's better than nothing, and so long as we're treating it properly, the end result should be valuable," he adds.

MedEffect, meanwhile, operates in a similar fashion and has similar limita- tions with regard to utility, experts say.

It is "a bit of an electronic dumpster," says Dr. David Juurlink, head of the Division of Clinical Pharmacology and Toxicology at Sunnybrook Health Sciences Centre and a scientist at the Institute for Clinical Evaluative Sciences, both in Toronto, Ontario. It's most useful as a tool for finding some evidence in support of a proposition, he adds. "If you have a hypothesis and can query right, you can find evidence for a hypothesis."

"Some doctors, pharmacists and patients will report to the database and those that do should be remunerated - but many don't use the database often. There are nuggets of information in there, but they're really quite hard to find," Juurlink says.

But others say the databases nevertheless have a value. They provide patients with an opportunity to report adverse effects and thus, make a contribution to knowledge, says Linda Wilhelm, an independent member of the Best Medicines Coalition, an alliance of organizations and individuals that seeks to promote safe use of drugs. "I think people checking MedEffect get confirmation. A patient will have a reaction and see if it's a reaction that's been listed. Often it hasn't. So they're helping other patients by providing that information. "It helps them be proactive and understand what's going on in their medication."

"Anytime I've gone into the doctor and said I thought the medication's doing something, they pull out the blue book, and if it's not listed there, well, then: 'the medication doesn't do that'," adds Wilhelm, who suffers from rheumatoid arthritis. "But the medication may do that because I'm on a biologic, on methotrexate, and Celebrex. Who's to say that because of those three medications interacting, that the medication isn't doing that."

Others say the move toward greater disclosure of adverse effects is inevitable, as demand from patients keeps rising and they are entitled to such information.

"Obviously people need to interpret this information cautiously, but I don't see why people should not be allowed to interpret that information. Who are we to say people should not have information?" asks Dr. Sonal Singh, assistant professor of general internal medicine at the Johns Hopkins University School of Medicine in Baltimore, Maryland.

"FDA and Health Canada are in the 19th century. This is the modern age. People are getting data from multiple sources. It's just going to happen, whether it's adverseevents.com, or clinical information. I think Health Canada and the FDA need to be ahead of the curve," Singh adds. - Tomek Sysak, Ottawa, Ont.

CMAJ 2012. DOI:10.1503/cmaj.109-4152

Editor's note: First of a two-part series.

Part 2: Physicians should be paid to report adverse drug reactions, experts say

(www.cmaj.ca/lookup/doi/10.1503

/cmaj.109-4153). 